\title{
Dietary Calcium Intake and Obesity
}

\author{
Sarina Schrager, $M D$
}

Obesity is increasing in the United States in epidemic proportions. Epidemiologic data suggest that people with high calcium intake have a lower prevalence of overweight, obesity, and insulin resistance syndrome. Studies in transgenic mice have demonstrated that calcium influences adipocyte metabolism. High calcium intake depresses levels of parathyroid hormone and 1,25-hydroxy vitamin D. These decreased hormone levels cause decreases in intracellular calcium, thereby inhibiting lipogenesis and stimulating lipolysis. High dietary calcium intakes also increases excretion of fecal fat and may increase core body temperature. Calcium from dairy products seems to have more of an impact than calcium from dietary supplements. Primary care providers should include recommendations about adequate calcium intake in standard dietary counseling about weight management. ( $\mathrm{J}$ Am Board Fam Pract 2005; 18:205-210.)

The prevalence of obesity is increasing dramatically in the United States. Current data estimate that more than $60 \%$ of the adult population between the ages of 20 and 74 are obese or overweight. ${ }^{1}$ The estimated annual direct and indirect costs of obesity in the United States are close to $\$ 100$ billion. $^{2}$ Obesity prevalence has increased dramatically in children as well. ${ }^{3,4}$ Overweight and obesity in children is directly associated with being overweight in adulthood. Obesity is related to multiple disease outcomes and has been shown to be related to increased mortality rates. In fact, obesity will soon overtake smoking as the most important modifiable cause of mortality in this country. Low calcium intake has been identified as a potential contributing factor to obesity. ${ }^{5}$

Many diet studies have found the average dietary calcium intake in people in the United States to be much lower than the current recommendations. ${ }^{6}$ Dietary calcium is important in building bone mass in children as well as in preventing osteoporosis in the elderly. Only $30 \%$ of children in the United States currently meet the recommended daily allowance (RDA) for calcium. The majority of dietary calcium consumed in the United States comes

Submitted, revised, 3 January 2005.

From the Department of Family Medicine, University of Wisconsin-Madison. Address correspondence to Sarina Schrager, MD, Department of Family Medicine, University of Wisconsin-Madison, 777 S. Mills St., Madison, WI 53715 (e-mail: sbschrag@wisc.edu). from dairy products. The upper limit recommended for calcium is $2500 \mathrm{mg}$ per day.

Low levels of dietary calcium and dairy products increase the risk of hypertension and insulin resistance syndrome (IRS). ${ }^{7-9}$ The Coronary Artery Risk Development in Young Adults (CARDIA) study $^{9}$ found that dairy product consumption was inversely proportional to all components of the IRS, including obesity. In this study, each daily serving of a dairy product was associated with $21 \%$ lower odds of developing IRS.

Epidemiologic studies have found an association between dietary calcium intake and obesity. Animal research has demonstrated a plausible physiologic mechanism for such an association, and some human clinical trials have produced suggestive results. The National Dairy Council has promoted the association between eating dairy products and obesity prevention in a national advertising campaign titled "The Weight Is Over."

This article will review the epidemiologic data supporting a relationship between dietary calcium intake and obesity, explain the physiologic basis for such a relationship, and present some supportive recent data in humans. The article will conclude with implications for primary care providers.

\section{Epidemiologic Data Supporting the Obesity- Dietary Calcium Relationship}

Several epidemiologic studies relate obesity prevalence and dietary calcium intake (Table 1). Zemel et $\mathrm{al}^{10}$ reanalyzed National Health and Nutrition 
Table 1. Human Studies of Calcium and Weight

\begin{tabular}{|c|c|c|c|}
\hline Author & Type of Study & Population & Results \\
\hline Zemel et al $^{10}$ & $\begin{array}{l}\text { Reanalysis of NHANES III data set } \\
\text { (SORT C) }\end{array}$ & $\begin{array}{l}380 \text { women } \\
7114 \text { men }\end{array}$ & $\begin{array}{l}\text { RR of being in the highest quartile for body } \\
\text { fat was reduced as calcium intake increased. } \\
\mathrm{RR} \text { in second quartile of } \mathrm{Ca}^{2+} \text { intake was } \\
0.75 \text {, in third } \mathrm{RR} \text { quartile was } 0.40 \text {, and in } \\
\text { highest quartile of } \mathrm{Ca}^{2+} \text { intake } \mathrm{RR} \text { was } 0.16 \\
(P<.0009 \text { for women, } P<.0006 \text { for men })\end{array}$ \\
\hline
\end{tabular}

Davies et $\mathrm{al}^{13} \quad$ Reanalysis of 5 clinical studies (2 crosssectional, 2 longitudinal, 1 RCT) of calcium and bone density (SORT C)

Heaney et $\mathrm{al}^{11} \quad$ Extension of reanalysis of above studies (SORT C)

Skinner et $\mathrm{al}^{14}$

Loos et $\mathrm{al}^{16}$

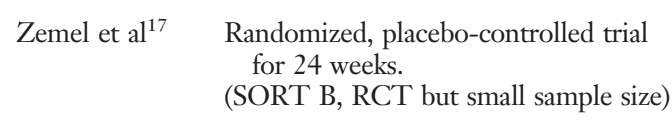

Drapeau et $\mathrm{al}^{15}$ Prospective cohort study (Quebec Family Study) measured twice (between 1989 and 1994 and also between 1995 and 2000)

(SORT B)

Prospective cohort study examining
children's body fat and calcium intake from 2 months old to 8 years (1)

Total sample size among all studies: 780 women in $3 \mathrm{rd}, 5$ th, 8 th decades

Young women (3rd decade) $n=348$

Midlife women (5th decade) $n=216$

52 white child-mother pairs completed entire study ( 25 boys, 27 girls)

248 volunteers between 18 and 65 years old (112 men, 136 women)

362 men (109 black, 253 white) and 462 women (201 black, and 261 white)

32 obese adults $(27$ women, 5 men)

Negative associations between calcium and body weight found in all studies for all 3 age groups. OR for being overweight (BMI $>26$ ) was 2.25 for young women who were in the lower half of calcium intakes. In RCT, calcium-treated women had significant weight loss over 4 years. Authors estimate that a $1000-\mathrm{mg}$ difference in calcium intake may be responsible for an 8 -kg difference in body weight.

Young women: at $25 \%$ for calcium intake, there was a $15 \%$ prevalence of overweight and a $1.4 \%$ prevalence of obesity. At a calcium intake equal to the current $\mathrm{RDA}$ the prevalence of overweight was only $4 \%$ and obesity $0.2 \%$. In midlife women, there was a significant decrease in yearly weight gain with increasing calcium intakes.

Dietary calcium was negatively related to body fat percentage in both boys and girls $(P=$ .02 to 0.04 ). Models including dietary calcium predicted $28 \%$ to $34 \%$ of variability in body fat percentage.

Increases in consumption of fruit and lowfat milk were associated with lower body fat and lower body weight.

Significant inverse associations were found for all men and white women between calcium intake and percentage of body fat. There was no significant association seen in black women.

All subjects were placed on a calorie-deficient diet. Then participants were randomized to 1 of 3 arms: standard diet, 400 to $500 \mathrm{mg}$ calcium with a placebo; high-calcium diet, standard diet supplemented with $800 \mathrm{mg}$ of calcium; and high-dairy diet, 1200 to 1300 $\mathrm{mg}$ of dietary calcium with placebo supplemented. Participants on the highdairy diet lost the most weight and the most truncal fat. The participants on the high calcium diet lost the second highest amount and the participants on the standard diet lost the least amount.

Shapses et al ${ }^{18}$ Randomized placebo-controlled trial

100 premenopausal and for 25 weeks. Data combined from 3 separate trials.

(SORT B, RCT with larger sample postmenopausal women

Subjects were randomized to receive either $1000 \mathrm{mg}$ of calcium in a supplement or a placebo. Weight loss was encouraged with behavior modification and nutrition education. Women participated in support groups and a subset of postmenopausal women was encouraged to consume one third of their calories with a meal replacement drink. There were no significant differences in body weight or change in body fat between the 2 groups.

NHANES III, National Health and Nutrition Examination Study III; RCT, randomized control trial; BMI, body mass index; SORT, strength of recommendation; RDA, recommended daily allowance; OR, odds ratio; RR, resistance ratio. 
Examination Study III (NHANES III) data and found that after controlling for energy intake and physical activity, body fat was lower in people with the highest calcium intake. There was a reduction in risk for obesity with each increasing quartile of calcium intake. At the highest quartile of calcium intake (an amount approximately equal to the current RDA for calcium), the risk of being in the highest body mass index quartile was reduced by $85 \%$.

Heaney et $\mathrm{al}^{11}$ reanalyzed data from 2 cohorts of women studied from 1984 to 1985 and 1995 through 1997. These 348 women were enrolled in studies examining calcium intake and bone density. The young women at the 25 th percentile of calcium intake for the group had a $15 \%$ prevalence of overweight. Women in the group whose calcium intake was equivalent to the current RDA for calcium had only a $4 \%$ prevalence of overweight. In the second cohort of midlife women, a reduction in average yearly weight gain was associated with increasing calcium intake.

Heaney et al ${ }^{12}$ also reanalyzed 6 observational studies and 3 clinical trials that were originally exploring dietary calcium intake and either bone density or blood pressure as outcome measures. This reanalysis found a consistent effect of higher dietary calcium intake and either body fat, body weight, or reduced midlife weight gain. In this pooled data set, each $300-\mathrm{mg}$ increase in daily calcium intake was associated with a $1-\mathrm{kg}$ decrease in body fat among children and a 2.5 - to $3-\mathrm{kg}$ decrease in body weight in adults.

Davies et $\mathrm{al}^{13}$ reanalyzed 5 clinical studies of calcium intake and bone density. The pooled data set included 780 women in their 30s, 50s, or 80 s. Four of the studies were observational, and one was a randomized controlled trial. There were significant negative associations between calcium intake and body weight. The odds ratio for being overweight in the young women was 2.25 for those below the 50th percentile for calcium intakes. In the controlled trial, women who received calcium had a significant weight loss over 4 years compared with the placebo group. The authors extrapolated that a $1000-\mathrm{mg}$ difference in calcium intake is associated with a 8-kg difference in body weight and that dietary calcium intake may explain approximately $3 \%$ of the change in weight. ${ }^{13}$

Several problems exist with data from reanalysis of previous trials such as those above. First, some of the same studies were included in both of the above reviews, which makes it hard to evaluate the results. ${ }^{12,13}$ Second, none of the trials were designed with body weight as an endpoint. Therefore, unknown confounding factors may exist that effect the data. Third, because the associations are derived from observational studies, no evidence of causality can be ascertained. For instance, it may be that the people who ingested more calcium were also less likely to eat at fast-food restaurants and were therefore less likely to be overweight or obese. In that case, the calcium intake was caused not by the lower risk of overweight or obesity but by another factor entirely. It is also unclear whether calcium itself has a major impact on body weight or whether the impact comes from some other component of dairy products.

Skinner et $\mathrm{al}^{14}$ demonstrated a negative relationship between dietary calcium intake and body fat in a group of 8-year-old children in his prospective study. In the author's statistical model, children could reduce their body fat by $0.4 \%$ simply by drinking an extra 8-oz glass of skim milk or 8 oz of low-fat yogurt each day. The CARDIA prospective study examined dairy consumption and several outcome variables associated with the IRS ${ }^{9}$ and found an inverse relationship between dairy consumption and all the components of the IRS, including obesity. The Quebec Family Study observed that calcium and dairy product intake induced changes in body composition (ie, decreased abdominal circumference) in a long-term observational study. ${ }^{15}$ The Health, Risk Factors, Exercise, Training, and Genetics (HERITAGE) Family Study, another long-term prospective study, found significant associations between low calcium intake and high levels of adiposity in white and black men and white women. These associations were not found in black women. ${ }^{16}$

\section{Prospective Studies in Humans}

The epidemiologic evidence suggests a strong relationship between dietary calcium intake and weight. However, there have been only 2 prospective controlled trials in humans using calcium supplementation as a variable and body weight as an outcome. One of the studies found a significant relationship between calcium supplementation and weight loss in people on a calorie-restricted $\operatorname{diet}^{17}$ whereas the other did not. ${ }^{18}$ 
In their 2004 study, Zemel et $\mathrm{al}^{17}$ randomized 32 obese adults to a standard calorie-deficient diet alone, a calorie-deficient diet supplemented with calcium, or a calorie-deficient diet supplemented with dairy products. Participants lost $6.4 \%$ body weight with the calcium-supplemented diet, $8.6 \%$ with the standard diet, and $10.9 \%$ with the high dairy $\operatorname{diet}(P<.01)$. It is interesting that truncal fat loss was significantly augmented with calcium and augmented even more by the high dairy diet (19\% of all fat lost on standard diet vs $50 \%$ of all fat lost on calcium-supplemented diet vs $66 \%$ of all fat lost on high-dairy diet, $P<.001)$.

Shapses et $\mathrm{al}^{18}$ performed 3 separate, randomized, placebo-controlled trials of 1000-mg calcium supplementation in 100 premenopausal and postmenopausal women. There were no significant differences between the calcium-supplemented group and the placebo group in body weight or body fat. Baseline calcium intakes ranged from 600 to 1000 $\mathrm{mg}$ per day in both groups. The calcium-supplemented group's calcium intakes averaged $1000 \mathrm{mg}$ more than the placebo group. Calcium supplementation in this trial did not accelerate weight loss. There was, however, a small nonsignificant difference between the supplemented and placebo groups in their mean total weight lost and the proportion of weight lost as fat, with the supplemented group losing more weight and a higher proportion of weight as fat.

\section{Proposed Mechanisms of Action}

There are 2 main physiologic mechanisms proposed to explain how calcium intake can affect body weight or body fat. The first is the effect of dietary calcium on intracellular calcium levels in adipocytes, and the second is the effect of dietary calcium on fatty acid absorption from the gastrointestinal tract.

\section{Effect of Dietary Calcium on Adipocytes}

Ninety-nine percent of a body's calcium content is stored in the extracellular space. The majority of extracellular calcium is stored in bones and teeth. Intracellular cytosolic soluble calcium mediates many metabolic pathways, including platelet aggregation and insulin resistance. Calcitropic hormones, such as parathyroid hormone (PTH) and 1,25-hydroxy vitamin $\mathrm{D}$, regulate intracellular calcium. Low dietary calcium intake stimulates high levels of PTH and 1,25-hydroxy vitamin D, which in turn stimulate high levels of intracellular calcium in adipocytes stimulating lipogenesis and inhibiting lipolysis. High dietary calcium intake depresses the levels of PTH and 1,25-hydroxy vitamin D, thereby causing lower levels of intracellular calcium and inhibiting lipogenesis and stimulating lipolysis. ${ }^{19,20}$ Therefore, calcium intake may directly affect whether adipocytes store or break down fat.

Results of studies in transgenic mice are consistent with the preceding observations. High-calcium diets were associated with a $51 \%$ decrease in adipocyte fatty acid synthase expression and activity and a 3 - to 5 -fold increase in lipolysis in mice. ${ }^{20} \mathrm{In}$ mice subjected to calorie restriction, low-calcium diets impeded body fat loss, and high-calcium diets accelerated fat loss. ${ }^{20}$ All the mice on calciumsupplemented diets exhibited increased core temperature as well, whereas the mice on the plain energy-restricted diet did not. A specific protein (uncoupling protein 2) is up-regulated in the calcium-supplemented mice, which may cause increased core temperature, although the mechanism of action is not clear. ${ }^{21}$

\section{Change in Fat Absorption}

The second proposed mechanism by which calcium may impact body weight is that increased dietary calcium seems to bind more fatty acids in the colon, thereby inhibiting fat absorption. Welberg et al, ${ }^{22}$ in a small 1994 study, showed that calcium supplementation increased the percentage of excretion of total fat as related to fat intake. The calcium supplementation in this study was either 2 or $4 \mathrm{~g}$. Denke et $\mathrm{al}^{23}$ supplemented 13 men with approximately $2 \mathrm{~g}$ of calcium per day in a 1993 study. The percentage of dietary fat excreted per day increased from $6 \%$ to $13 \%$ with calcium supplementation. The Nestle Company supplemented chocolate with $900 \mathrm{mg}$ of calcium and tested the fecal fat content of 10 men in a double-blind crossover study. Calcium supplementation of chocolate increased fecal fat from 4.4 to $8.4 \mathrm{~g}$ per day $(P<$ $.0001){ }^{24}$ These studies show a small effect of calcium on fat absorption that probably contributes to the antiobesity effects but does not explain it entirely. The degree of fecal fat loss in these studies of high calcium supplementation is only approximately $3 \%$ of that induced by medications such as orlistat. $^{25}$ 


\section{Dairy versus Calcium Supplements}

Several of the previously reviewed studies suggest that calcium from dairy products affects weight loss more than calcium derived from dietary supplements. ${ }^{17}$ Preliminary data point to some other component in dairy products, possibly whey protein, effecting the weight-loss effect of calcium. ${ }^{26}$ Whey protein provides a multitude of bioactive substances that may work synergistically with the calcium to alter lipid metabolism.

\section{Implications for Primary Care Providers}

Calcium is not a magic bullet in the battle against obesity, although it may play a small, but significant, role. The affect of dairy products or calcium is probably greatest in those people whose adipocyte status is changing, such as during weight loss, ageassociated weight gain, and growth. ${ }^{27}$ Women, in particular, are at high risk for age-associated weight gain after menopause. Calcium contributes to maintenance of strong bones and may modulate weight gain in postmenopausal women. As such, primary care providers can target postmenopausal women and overweight or obese adults and children for extra counseling about calcium intake. (Strength of Recommendation level C: expert opinion. ${ }^{28}$ ) An important concept to remember is that calcium does not seem to be effective unless a calorie restriction is already in place. Replacing other sources of protein with low-fat dairy products may help augment weight loss. Adequate calcium intake, preferably from dairy products, may be especially important in people who have hypertension or components of the IRS. All patients should be encouraged to consume 3 to 4 servings of lowfat dairy products every day. Primary care providers should include recommendations about calcium intake in standard dietary counseling about weight management.

\section{References}

1. National Center for Health Statistics. Prevalence of overweight and obesity among adults [monograph on the Internet]. Hyattsville (MD): National Center for Health Statistics, Centers for Disease Control and Prevention, US Department of Health and $\mathrm{Hu}-$ man Services; 2005 [cited 18 Mar 2005]. Available from: http://www.cdc.gov/nchs/products/pubs/pubd/ hestats/overweight 99. htm.

2. Weight-Control Information Network. Statistics related to overweight and obesity [monograph on the Internet]. Bethesda (MD): Weight-Control Infor- mation Network, National Institute of Diabetes and Digestive and Kidney Diseases; 2005 [cited 18 Mar 2005]. Available from: http://win.niddk.nih.gov/ statistics/index.htm, 2001.

3. Ogden CL, Flegal KM, Carroll MD, Johnson CL. Prevalence and trends in overweight and obesity among US children and adolescents. JAMA 2002; 288:1728-32.

4. Hedley AA, Ogden CL, Johnson CL, Carroll MD, Curtin LR, Flegal KM. Prevalence of overweight and obesity among US children, adolescents and adults, 1999-2000. JAMA 2004;291:2847-50.

5. Zemel M, Gottlieb B. The calcium key. Hoboken (NJ): John Wiley and Sons, Inc.; 2004.

6. Fleming K, Heimbach JT. Consumption of calcium in the US: food sources and intake levels. J Nutr 1994;124:1426S-30S.

7. Griffith L, Guyatt GH, Cook RJ, Bucher HC, Cook DJ. The influence of dietary and non-dietary calcium supplementation on blood pressure: an updated metaanalysis of randomized controlled trials. Am J Hypertens 1999;12:84-92.

8. McCarron D, Reusser ME. Finding consensus in the dietary calcium-blood pressure debate. J Am Coll Nutr 1999; 18:398S-405S.

9. Pereira M, Jacobs DR, Van Horn L, Slattery ML, Kartashov AI, Ludwig DS. Dairy consumption, obesity, and the insulin resistance syndrome in young adults: the CARDIA Study. JAMA 2002;287:2081-9.

10. Zemel M, Shi H, Greer B, DiRienzo D, Zemel PC. Regulation of adiposity by dietary calcium. FASEB J 2000;14:1132-8.

11. Heaney R. Normalizing calcium intake: projected population effects for body weight. J Nutr 2003;133: 268S-70S.

12. Heaney R, Davies KM, Barger-Lux MJ. Calcium and weight: clinical studies. J Am Coll Nutr 2002; 21:152S-5S.

13. Davies K, Heaney RP, Recker RR, et al. Calcium intake and body weight. J Clin Endocrinol Metab 2000;85:4635-8.

14. Skinner J, Bounds W, Carruth BR, Ziegler P. Longitudinal calcium intake is negatively related to children's body fat indexes. J Am Diet Assoc 2003;103: 1626-31.

15. Drapeau V, Despres JP, Bouchard C, et al. Modifications in food group consumption are related to long-term body weight changes. Am J Clin Nutr 2004;80:29-37.

16. Loos RJ, Rankinen T, Leon AS, et al. Calcium intake is associated with adiposity in black and white men and white women of the HERITAGE family study. J Nutr 2004;134:1772-8.

17. Zemel M, Thompson W, Milstead A, Morris K, Campbell P. Calcium and dairy acceleration of weight and fat loss during energy restriction in obese adults. Obes Res 2004;12:582-90.

18. Shapses SA, Heshka S, Heymsfield SB. Effect of 
calcium supplementation on weight and fat loss in women. J Clin Endocrinol Metab 2004;89:632-7.

19. Zemel M. Regulation of adiposity and obesity risk by dietary calcium: mechanisms and implications. J Am Coll Nutr 2002;21:146S-51S.

20. Zemel M. Mechanisms of dairy modulation of adiposity. J Nutr 2003;133:252S-6S.

21. Shi H, Norman AW, Okamura WH, Zemel MB. 1, $\alpha, 25$-Dihydroxyvitamin D3 inhibits uncoupling protein 2 expression in human adipocytes. FASEB J 2002;16:1808-10.

22. Welberg J, Monkelbaan JF, deVries EG, et al. Effects of supplemental dietary calcium on quantitative and qualitative fecal fat excretion in man. Ann Nutr Metab 1994;38:185-91.

23. Denke M, Fox MM, Schulte MC. Short term dietary calcium fortification increases fecal saturated fat con- tent and reduces serum lipids in men. J Nutr 1993; 123:1047-53.

24. Shahkalili Y, Murset C, Meirim I, et al. Calcium supplementation of chocolate: effect on cocoa butter digestibility and blood lipids in humans. Am J Clin Nutr 2001;73:246-52.

25. Parikh S, Yanovski JA. Calcium intake and adiposity. Am J Clin Nutr 2003;77:281-7.

26. Shah NP. Effects of milk-derived bioactives: an overview. Br J Nutr 2000;84 Suppl 1:S3-10.

27. Teegarden D, Zemel MB. Dairy product components and weight regulation: symposium overview. J Nutr 2003;133:243S-4S

28. Ebell MH, Siwek J, Weiss BD, et al. Strength of Recommendation Taxonomy (SORT): a patientcentered approach to grading evidence in the medical literature. J Am Board Fam Pract 2004;17:59-67. 